\title{
Transient prediction of annular pressure between packers in high-pressure low-permeability wells during high-rate, staged acid jobs
}

\author{
Liangliang Ding ${ }^{1,2}$, Jiyang Rao ${ }^{1}$, and Chengyu $\mathrm{Xia}^{3, *}$ \\ ${ }^{1}$ College of Mechatronic Engineering, Southwest Petroleum University, Chengdu 610500, China \\ ${ }^{2}$ State Key Laboratory of Oil \& Gas Reservoir Geology and Exploitation (Southwest Petroleum University), Chengdu 610500, China \\ ${ }^{3}$ College of Mechanical Engineering, Yangtze University, Jingzhou 434023, China
}

Received: 6 January 2019 / Accepted: 8 June 2020

\begin{abstract}
For high-pressure low-permeability wells, wellbore temperature drops drastically in high-rate and multistage acid fracturing process. Under the combined action of the swelling of tubing string and the contraction of annular fluid between packers, annular pressure between packers undergoes violent transient change in staged acid jobs, thereby deteriorating loading on the tubing string and packers. Based on the principle of energy conservation and wellbore heat conduction, the transient prediction of two-dimensional (2D) wellbore temperature field under pumping injection condition was established by considering the effects of heat generated by friction and convection heat exchange. Moreover, the effects of wellbore temperature/pressure changes on the annular volume between packers were analyzed. Furthermore, in combination with the transient prediction model of wellbore temperature, PVT state equation of annular fluid, the calculation model of tubing string radial deformation and the transient seepage equation of the formation, the transient prediction model of annular pressure between packers in high-pressure low-permeability wells was established. Finally, by taking a high-pressure low-permeability well as an example, annular pressure between packers was calculated and the forces on the packers and tubing string were analyzed. According to the prediction results, the tubing string, which was regarded to be safe using conventional design method, exhibited an extremely high risk of failure after taking into account the decrease in annular pressure between packers. Therefore, the decrease in annular pressure should be fully considered in the design of tubing string for high-pressure low-permeability wells in multistage acid fracturing process. In combination with sensitivity analysis results, it can be concluded that formation permeability, injection rate and formation pressure all affected the change in annular pressure between packers.
\end{abstract}

\section{Introduction}

For some considerations in design and construction, one or more enclosed fluid space may exist in oil-gas well structures such as annulus between tubing and casing with packer strings and various casing annulus including free casing segment. During well testing and production, fluid temperature in various enclosed annulus within the wellbore increases with the rapid increase in wellbore temperature, which can lead to the increasing pressure in the annular enclosed space and may trigger a series of problems mainly including the failures of tubing string and casing string as well as the elevation of wellhead (Hasan et al., 2010; Yang et al., 2013b). For example, in Marlin Oilfield owned by BP Corporation, the well was finally abandoned because of the

\footnotetext{
* Corresponding author. 93345890@qq. com
}

failure of production casing caused by pressure in casing annulus (Bradford et al., 2002; Gosch et al., 2004). At the Pompano A-31 well in the Gulf of Mexico, the drilling tool was jammed on account of casing deformation under annular pressure alternation (Pattillo et al., 2006).

Since the 1980s, scholars all over the world have conducted a great deal of research on the annular pressure in wellbore enclosed space, examined the annular pressure induced by the rise in wellbore temperature, established the related theoretical calculation models (Halal et al., 1994; Hu et al., 2012; Oudeman and Kerem, 2006; Yin and Gao, 2014) and raised some risk mitigation measures in accordance with different well conditions and requirements (Ezell et al., 2010; Sathuvalli et al., 2005; Tahmourpour et al., 2010; Williamson et al., 2003).

Recently, scholars have mainly focused on the increase in annular increase induced by pressure/temperature 
changes, while the induced decrease in annular pressure has been poorly investigated (Bellarby et al., 2013). In recent years, with gradual depletion of conventional gas/oil resources, more and more low-permeability and ultra-lowpermeability oil/gas reservoirs have been exploited. A typical technology in the development of low-permeability oil/gas reservoirs is high-pumping-pressure, high-rate and multistage acid fracturing jobs, during which the wellbore temperature drops drastically. Under the combined action of the swelling of tubing string and annular fluid contraction between packers, the annular pressure drops, which can easily result in excessive inner and outer pressure difference of the packer tubing and very large pressure difference between top and bottom of the packer. Accordingly, the loading conditions in the operating tubing strings and the packer deteriorate, thereby easily causing the failures of tubing string and packers. At present, both tubing string and packers are generally designed without considering the transient change in annular pressure between packers. It is generally assumed that the annular pressure is equivalent to the formation pressure, but the loading conditions of the tubing strings and downhole tools are more severe.

To overcome the shortcomings in traditional string design, this study establishes a two-dimensional (2D) transient prediction model of wellbore temperature field based on the fundamental equation of energy conservation. Then, the model is calculated according to the variations in the annular volume between packers with wellbore temperature/pressure, during which the transient annular volume change, transient annular fluid volume change and the seepage characteristics of the connected strata outside the annulus are taken into full account. Moreover, the transient prediction model of annular pressure between packers is constructed and the related prediction method is validated by an application example.

\section{Analysis of the failure of tubing string}

It was reported that tubing string failures occurred in many low-permeability oil wells of the Tarim Basin in western China during high-rate, staged acid jobs. The failure positions were mainly located in the upper packers or the tubing string between packers. Similar failure processes can also be observed in other locations. A typical failure process is described below. During the staged acid jobs in the lower packer, tubing-casing annular pressure increases suddenly, and simultaneously, tubing pressure drops. At that moment, tubing pressure and casing pressure connection can be observed and the fracturing operation should be stopped in advance. After the occurrence of accidents, the workers have found fractures in the central spindles of packers in many wells during workover operation. Figures 1 and 2 display tooth hole shrinkage and the fracture surface of the central spindle of upper 7-inch packer on top of a well.

Before the application in the well, these tubing strings should be fully verified in terms of tubing string mechanics using internationally accepted tubing string design methods and software. When tubing string failures occurred, many experts from various fields were invited for analysis.

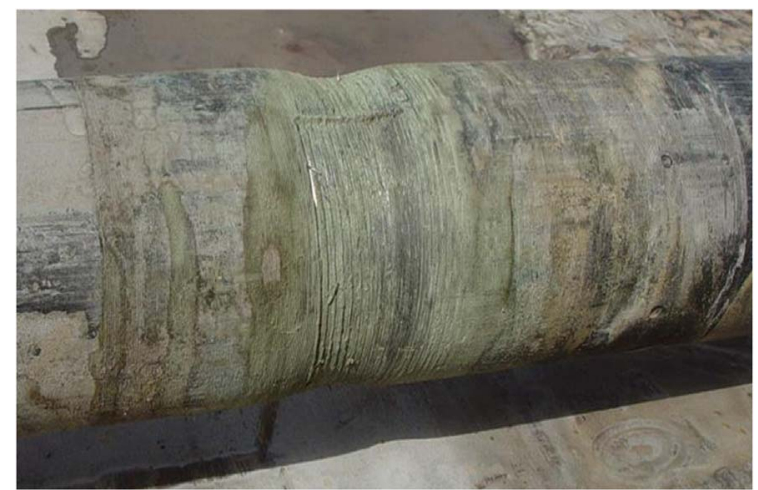

Fig. 1. Photograph of recovered, diameter shrinkage at mandrel teeth.

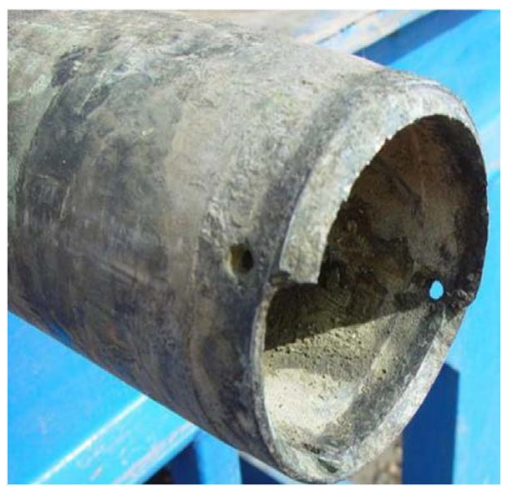

Fig. 2. Photograph of recovered, mandrel fracture section of upper 7-inch packer.

It was found that the loading on the packer was always within the designed envelope curves and the calculated values of triaxial stress in the pipe, internal pressure strength, collapse resistance and axial force safety coefficient all exceeded the designed values, while all packers and tubing strings in the wells satisfied the design requirements.

Based on the results of systematic analysis of various kinds of wells, it is found that the annular pressure between the packers in fracturing process is assumed to be equivalent to the pore pressure in the stratum outside the annulus when designing tubing strings using typical design methods. However, with regard to low-permeability wells represented by many of the failure wells in the Tarim Basin in western China, the annular pressure between packers undergoes transient change during high-rate, staged acid jobs. Therefore, it is unreasonable to assume that the annular pressure between packers equals to the pore pressure in the stratum outside the annulus.

For the above representative wells (annulus between packers shown in Fig. 3), wellbore temperature drops rapidly when performing high-rate and multistage acid fracturing on the lower strata. During the well operation, the maximum annular temperature between packers can reach up to $90{ }^{\circ} \mathrm{C}$. The decrease in wellbore temperature can induce fluid contraction in the packer annulus, thereby 


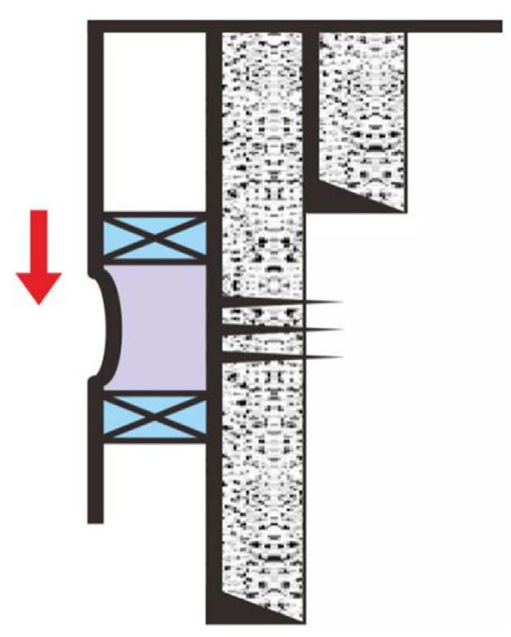

Fig. 3. Annular space between packers.

leading to the reduction in annular pressure. For lowpermeability formation, the seepage velocity of pressure from the formation to the annulus is extremely small. This can lead to significant decrease in annular pressure between packers in multistage acid fracturing process and the deterioration of loading conditions on two packers and the tubing string between them. Therefore, based on the prediction of wellbore pressure/temperature field, the simulation of annular volume between packers and the seepage rules in the formation during fracturing process, this study first realized the transient prediction of annular pressure between packers in multistage acid fracturing process and then focused on mechanical analysis of tubing strings.

\section{Prediction of wellbore temperature field}

During high-rate, staged acid jobs in high-pressure lowpermeability wells, the change in wellbore temperature field follows the principle of energy conservation (Ding, 2011):

$$
\mathrm{d} Q_{\text {all }}+\mathrm{d} W_{\text {all }}=\mathrm{d} E_{\text {all }},
$$

where $\mathrm{d} Q_{\text {all }}$ denotes the heat flowing into the wellbore unit in unit time, with a unit of $\mathrm{J} /(\mathrm{s} \mathrm{m}) ; \mathrm{d} W_{\text {all }}$ denotes the work done by the surrounding on the wellbore unit, with a unit of $\mathrm{J} /(\mathrm{s} \mathrm{m})$; and $\mathrm{d} Q_{\text {all }}$ denotes the energy variation of the wellbore unit in unit time, with a unit of $\mathrm{J} /(\mathrm{s} \mathrm{m})$.

As shown in Figure 4, by selecting some units including the fluid in the oil pipe, the tubing string, the annular fluid between string and casing, the casing string, the cement sheath and the formation, the borehole system is divided into a certain number of control units along both axial and radial directions. Then, in combination with heat conduction and heat convection theories of various media in the borehole system, the control equations for transient prediction of wellbore temperature field in 2D cylindrical coordinate system are established (Ai et al., 2015; Wang et al., 2018).

(1) Liquid unit in the oil pipe

Figure 5 displays the established physical model of heat convection of liquid in the tubing string. The quantity of

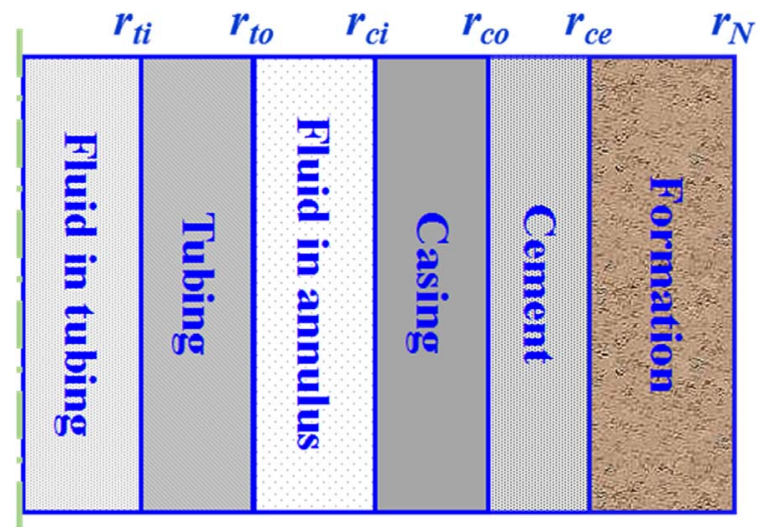

Fig. 4. Thermal transmission in radial direction in $2 \mathrm{D}$ wellbore.

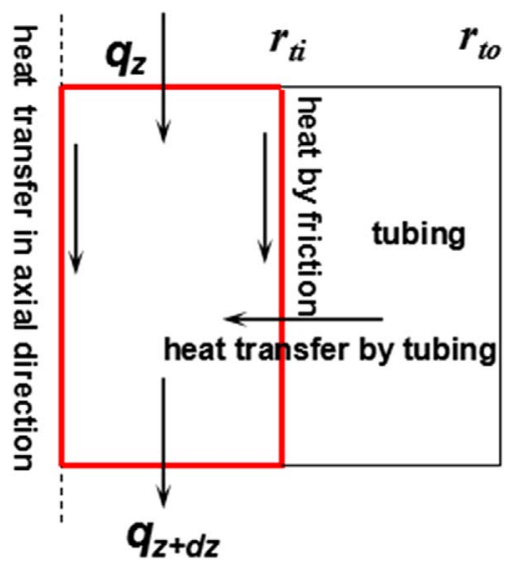

Fig. 5. Fluid element inside the tubing.

heat flowing from the external surroundings to the unit mainly includes the heat carried by the liquid during the flowing process in the oil pipe, axial heat conduction and radial heat convection along the tubing string wall. Furthermore, the viscous frictional work induced by the fluid's viscous friction is taken into account. The energy-balance equation can be written as (Hasan and Kabir, 1991; Yang, et al., 2013a):

$$
k_{t} \frac{\partial^{2} T}{\partial z^{2}}+\frac{2 h_{t i}\left(T_{t}-T_{l}\right)}{r_{t i}}+\frac{Q_{l}}{A_{l}}=\rho_{l} c_{l} \frac{\partial T}{\partial t}+\rho_{l} c_{l} v_{l} \frac{\partial T}{\partial z}
$$

where the subscript $i$ represents the fluid in the oil pipe, the tubing string and the internal face of the string, respectively $(i=l, t$ and $t i) ; k$ denotes the coefficient of heat conduction, with a unit of $\mathrm{W} /(\mathrm{m} \mathrm{K}) ; T$ denotes the temperature, with a unit of $\mathrm{K}$; $z$ denotes the well depth, with a unit of $\mathrm{m}$; $h$ denotes the coefficient of interfacial heat convection, with a unit of $\mathrm{W} /\left(\mathrm{m}^{2} \mathrm{~K}\right) ; r$ denotes the unit radius, with a unit of $\mathrm{m} ; Q$ denotes the friction-induced heat, with a unit of $\mathrm{J} / \mathrm{s} ; A$ denotes the unit's crosssectional area, with a unit of $\mathrm{m}^{2} ; \rho$ denotes the fluid density, with a unit of $\mathrm{kg} / \mathrm{m}^{3} ; c$ denotes the specific heat, with a unit of $\mathrm{J} /(\mathrm{kg} \mathrm{K}) ; t$ denotes time, with a unit of $\mathrm{s}$; and $v$ denotes the fluid's flowing velocity, with a unit of $\mathrm{m} / \mathrm{s}$. 


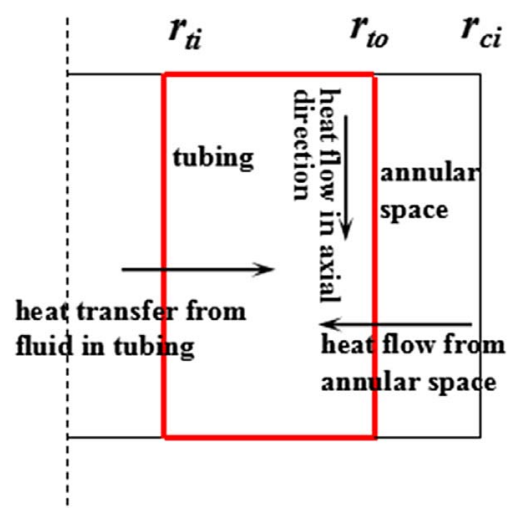

Fig. 6. Tubing string element.

\section{(2) Tubing string unit}

Figure 6 displays the established physical model of heat conduction along the tubing string wall. The heat from the outside world to the control unit includes axial heat conduction in the tubing string and radial heat conduction along the tubing string wall. Since the fluid's friction heating is taken into account, it can be assumed that the external surroundings did not apply work on the unit. The energy balance equation in the tubing string can be written as:

$k_{t} \frac{\partial^{2} T}{\partial z^{2}}+\frac{4 r_{t o} k_{c l}\left(T_{c l}-T_{t}\right)}{\left(r_{c i}-r_{t o}\right) \cdot\left(r_{t o}^{2}-r_{t i}^{2}\right)}+\frac{2 r_{t i} h_{t i}\left(T_{l}-T_{t}\right)}{r_{t o}^{2}-r_{t i}^{2}}=\rho_{t} c_{t} \frac{\partial T}{\partial t}$,

where the subscript $i$ represents the external wall of the tubing string, annular fluid and annular internal diameter, respectively $(i=t o, c l$ and $c i)$.

\section{(3) Other units}

The energy balance equation of the other units in the wellbore can be written as:

$$
k_{w} \frac{\partial^{2} T}{\partial z^{2}}+k_{w} \frac{\partial^{2} T}{\partial r^{2}}+\frac{k_{w}}{r} \frac{\partial T}{\partial r}=\rho_{w} c_{w} \frac{\partial T}{\partial t},
$$

where the subscript $i$ represents the annular fluid, the casing string, the cement sheath and the formation unit, respectively $(i=w)$.

By performing differential meshing discretization on equations (2)-(4), the solutions are acquired by means of difference method so as to derive the variation of temperature field on 2D profile of the whole wellbore with time during the multistage acid fracturing process.

\section{Transient prediction of annular pressure between packers}

This study also assumes that the system is axially symmetrical around the central line of the oil pipe, the oil pipes and casing pipes are isotropic, and various physical parameters of the materials in the whole wellbore system remain constant. The enclosed annulus between packers is full of completion fluid, and the fluid pressure in the enclosed space satisfies the following function (Williamson et al., 2003):

$$
P=P\left(T, V_{p}, m\right)
$$

where $P$ denotes the annular pressure between packers, with a unit of $\mathrm{MPa} ; V_{p}$ denotes the annular volume between packers, with a unit of $\mathrm{m}^{3}$; and $m$ denotes the annular fluid mass between packers, with a unit of $\mathrm{kg}$.

According to equation (5), annular pressure between packers in multistage acid fracturing process is determined by three factors, namely, fluid contraction induced by the decrease in fluid temperature, change in annular volume and change in annular fluid amount:

$$
\Delta P=\Delta P_{t}+\Delta P_{v}+\Delta P_{m}
$$

where $\Delta P_{t}$ denotes the change in annular pressure between packers induced by thermal expansion/contraction of annular fluid, with a unit of MPa; $\Delta P_{v}$ denotes the change in annular pressure between packers induced by the change in annular volume, with a unit of $\mathrm{MPa}$; and $\Delta P_{m}$ denotes the change in annular pressure between packers induced by the change in annular fluid mass, with a unit of MPa.

The change in annular pressure between packers caused by fluid contraction with decrease in temperature can be calculated as (Rizkiaputra et al., 2016):

$$
\Delta P_{t}=\frac{a_{a t}}{k_{T}} \Delta T
$$

where $k_{T}$ denotes the isothermal compressibility of the fluid between packers, with a unit of $\mathrm{MPa}^{-1} ; a_{a t}$ denotes the thermal coefficient of annular fluid, with a unit of ${ }^{\circ} \mathrm{C}^{-1} ; \Delta T$ denotes the decrease in annular temperature between packers, with a unit of ${ }^{\circ} \mathrm{C}$.

The change in annular pressure between packers induced by fluid expansion or contraction with varying temperature, denoted as $\Delta P_{t}$, can be calculated based on the prediction results of wellbore temperature as well as compressibility coefficient and thermal coefficient of annular fluid between packers.

\subsection{Prediction of the change in annular volume between packers}

The change in annular pressure between packers induced by the change in annular volume can be calculated as:

$$
\Delta P_{v}=-\frac{1}{k_{T} V_{a}} \Delta V_{a},
$$

where $\Delta V_{a}$ denotes the increment in annular volume between packers, with a unit of $\mathrm{m}^{3}$, and $V_{a}$ denotes the annular fluid volume between packers, with a unit of $\mathrm{m}^{3}$.

By taking into account the effects of wellbore pressure/ temperature changes on annular fluid between tubing string and the packer, the transient increment in annular volume between packers in multistage acid fracturing process, denoted as $\Delta V_{a}$, is then calculated.

\section{(1) Radial contraction of the tubing string}

During staged acid jobs, the tubing string shows radial contraction with the decrease in wellbore temperature, thereby leading to the increase in enclosed annular volume between packers. The radial displacement of the tubing 
string induced by temperature change can be calculated as (Zhang. et al., 2010):

$$
S_{1}=\frac{1+\mu}{1-\mu} \frac{\alpha_{a g}}{r} \int_{r_{\mathrm{ti}}}^{r} \Delta \operatorname{Tr} \mathrm{d} r
$$

where $S_{1}$ denotes the radial displacement at any point on the string, with a unit of $\mathrm{m} ; \mu$ denotes the steel pipe's Poisson's ratio, dimensionless; $\alpha_{a g}$ denotes the string steel's thermal expansion coefficient, with a unit of $1 /{ }^{\circ} \mathrm{C}$; $r$ denotes the distance between any point on the string and the axis of the string, with a unit of $\mathrm{m}$; and $r_{t i}$ denotes the radius of the pipe, with a unit of $\mathrm{m}$.

Under constant temperature difference, the change in external diameter of the pipe can be calculated as:

$$
S_{1}=\alpha_{\mathrm{ag}} \Delta T \frac{1+\mu}{1-\mu} \frac{r_{\mathrm{to}}^{2}-r_{\mathrm{ti}}^{2}}{2 r_{\mathrm{to}}}
$$

where $r_{t 0}$ denotes the external diameter of the pipe, with a unit of $\mathrm{m}$.

The change in annular volume induced by the pipe's radial contraction can be calculated as (Yang et al., 2013b):

$$
\Delta V_{1}=\pi\left[\left(r_{t 0}+\mu_{r}\right)^{2}-r_{t 0}^{2}\right] L_{a}
$$

where $\Delta V_{1}$ denotes the change in annular volume induced by the pipe's radial contraction, with a unit of $\mathrm{m}^{3}$, and $L_{a}$ denotes the annular length between packers, with a unit of $\mathrm{m}$.

\section{(2) Contraction of the fluid}

With the decrease in temperature, the fluid in the enclosed annular space exhibits contraction, which can lead to the change in annular volume between packers. The change in annular volume can be calculated as:

$$
\Delta V_{2}=\alpha_{a t} \pi \Delta T\left(r_{c}^{2}-r_{t 0}^{2}\right) L_{a}
$$

where $\Delta V_{2}$ denotes the change in annular volume induced by the fluid contraction, with a unit of $\mathrm{m}^{3}$.

\section{(3) Radial expansion of oil pipe}

Due to the decrease in enclosed annular pressure, the oil pipe is under pressure and exhibits radial expansion on the external surface. The change in the external diameter of the oil pipe induced by the decreasing annular pressure, denoted as $S_{2}$ (with a unit of $\mathrm{m}$ ), can be calculated as (Oudeman and Kerem, 2006):

$$
S_{2}=r_{t 0} \Delta P \frac{(1+\mu)\left[r_{t i}^{2}+2(1-2 \mu) r_{t 0}^{2}\right]}{E_{t}\left(r_{t o}^{2}-r_{t i}^{2}\right)}
$$

where $E_{t}$ denotes the oil pipe's elastic modulus, with a unit of MPa. Therefore, the reduction in annular volume induced by radial expansion, denoted as $\Delta V_{3}$ (with a unit of $\mathrm{m}^{3}$ ), can be calculated as:

$$
\Delta V_{3}=\pi\left[\left(r_{t o}^{2}+S_{1}\right)^{2}-\left(r_{t 0}+S_{1}-S_{2}\right)^{2}\right] L_{a} .
$$

\section{(4) Expansion effect of annular fluid}

The decrease in annular pressure not only induces the swelling of the tubing string but also the expansion of annular fluid. The induced volume increment can be calculated as (Azzola et al., 2007):

$$
\Delta V_{4}=\frac{\pi}{E_{t}}\left(r_{c}^{2}-r_{t 0}^{2}\right) \Delta P L_{a},
$$

where $\Delta V_{4}$ denotes the change in annular volume induced by the expansion of annular fluid, with a unit of $\mathrm{m}^{3}$, and $E_{t}$ denotes the bulk elastic modulus of the annular fluid, with a unit of MPa.

\section{(5) Change in annular volume}

According to equations (11)-(15), the change in the enclosed annular volume can be calculated as:

$$
\Delta V_{\mathrm{a}}=\Delta V_{1}+\Delta V_{2}+\Delta V_{3}+\Delta V_{4} .
$$

\subsection{Prediction of pressure transfer between annulus and formation}

During the pumping-injection operation, annular pressure between packers drops steadily. Under the pressure difference between formation and annulus, the pressure in the perforated formation outside the annulus may exhibit transient seepage flow, which can result in the change in annular fluid mass between packers. Transient flowing behavior can be described as (Kan et al., 2016):

$$
P_{i}-P_{w f}=\frac{Q \mu}{4 \pi k h} E_{i}\left(\frac{\emptyset \mu c_{r} r_{o h}^{2}}{4 k t}\right)
$$

where $P$ denotes the annular pressure between packers, with a unit of $\mathrm{MPa} ; P_{i}$ denotes the pressure of the permeable formation outside the annulus between packers, with a unit of $\mathrm{MPa}$; $Q$ denotes the production rate, with a unit of $\mathrm{kg} / \mathrm{m}^{3} ; k$ denotes overall permeability, with a unit of $D ; h$ denotes the thickness of the permeable formation, with a unit of $\mathrm{m}$; $\Phi$ denotes the porosity of the permeability formation, with a unit of $\% ; \mu$ denotes the formation's fluid viscosity, with a unit of $\mathrm{MPa} s ; r_{o h}$ denotes the drainage radius, with a unit of $\mathrm{m}$; $t$ denotes the seepage time in the formation, with a unit of $\mathrm{h} ; \mathrm{Cr}$ denotes the total compression coefficient of the permeable formation, with a unit of $\mathrm{MPa}^{-1}$; and $E_{i}$ is the exponential integral term.

According to equation (17), the seepage velocities from formation to annulus under different pressures, denoted as $Q$, can be calculated. Therefore, the change in annular pressure induced by formation pressure transfer can be calculated as:

$$
\Delta P_{m}=Q \Delta t \frac{1}{k_{T} V_{a}} .
$$

\subsection{Solution to the theoretical model}

During high-rate and multistage acid fracturing process in high-pressure low-permeability wells, annular fluid temperature drops drastically. Due to the constraints of packers and pipe wall, annular fluid cannot be freely contracted, which can cause the decrease in annular pressure and thus induce the swelling of tubing string and the reduction in annular 
volume. The reduction in annular volume can enhance annular pressure, which can also increase the annular volume and generate additional pressure on the expansion of fluid. In turn, the pressure can react on the oil pipe and change the annular volume again, while the change in volume can also lead to the change in pressure. Further, after the decrease in annular pressure, pressure difference between annulus and the external formation is produced. Under this pressure difference, seepage may occur from low-permeability formation to annulus, thereby resulting in the rise in annular pressure. Therefore, the change in annular pressure between packers is determined by three factors, namely, thermal fluid contraction, annular volume change and annular fluid mass change. Moreover, these factors are coupled, and the change in annular pressure with the pumping-injection time, denoted as $\Delta P$, can also be solved via iterative computation. Figure 9 displays the detailed calculation procedures.

As shown in Figure 7, the change in annular pressure can be calculated as described below. Firstly, the time step is determined, and then, wellbore temperature distribution at different moments in multistage acid fracturing process is calculated. In the calculation, initial change in annular pressure, denoted as $\Delta P_{v}$, can be assumed. According to equations (11), (12), (14) and (15), the change in annular pressure induced by the change in annular volume, denoted as $\Delta P_{v}$, is calculated. The acquired results of $\Delta P_{v}$ in two calculations are compared and the error is calculated. If the error is within the allowable range, $\Delta P_{v}$ is output and the calculation continues; otherwise, the iterative calculation restarts until the calculation results satisfy the required accuracy. According to equation (7), the decrease in annular pressure, denoted as $\Delta P_{t}$, induced by the contraction of annular fluid with decreasing temperature, is calculated. After $\Delta P_{t}$ and $\Delta P_{v}$ are obtained, the change in annular pressure induced by seepage between annulus and formation, denoted as $\Delta P_{m}$, is calculated in accordance with the difference between annular pressure and formation pressure. Given the total change in annular pressure $(\Delta P)$, the total change in annular pressure are recalculated after the recalculation of $\Delta P_{t}$ and $\Delta P_{v}$. The values of $\Delta P$ in two calculations are compared and the error is calculated. If the error is within the allowable range, $\Delta P$ is output and the calculation continues; otherwise, the iterative calculation restarts until the calculated results reach the required precision. Subsequently, the total change in annular pressure at the next moment, denoted as $\Delta P$, is calculated according to the above steps. Finally, the calculation ends when the calculation results at all moments are acquired.

\section{Calculation in an example well}

This study focused on a high-pressure low-permeability well for further analysis. The detailed parameters are listed below. The depth of the drilling well is $5000 \mathrm{~m}$, the middle pressure in upper perforated formation is $90 \mathrm{MPa}$, the temperature on the bottom of wellbore is $136{ }^{\circ} \mathrm{C}$, dual-packer is employed for staged acid jobs, the depths of two packers are $4510 \mathrm{~m}$ and $4850 \mathrm{~m}$, the pumping pressure in construction

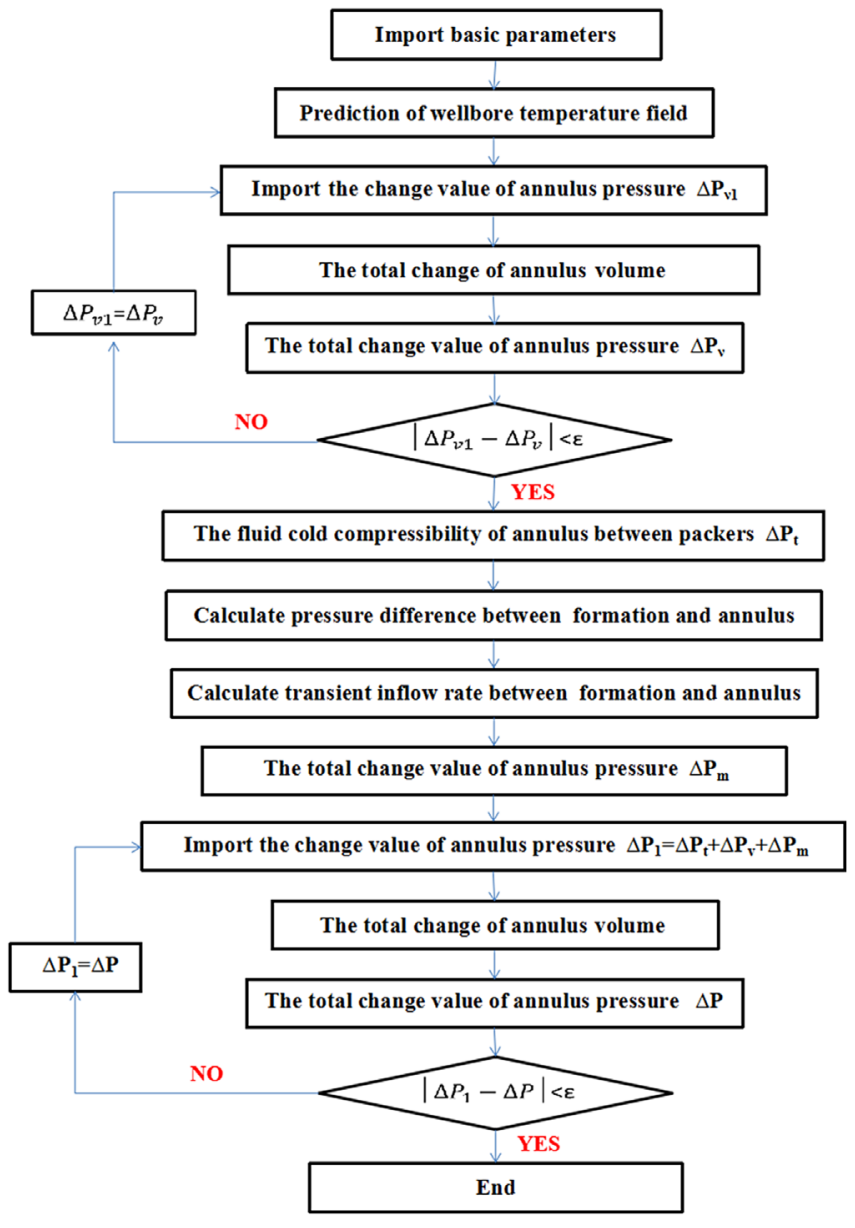

Fig. 7. Calculation flow diagram for the mathematical model.

ranges from 80 to $90 \mathrm{MPa}$, and the displacement in the construction is $5-6 \mathrm{~m}^{3} / \mathrm{min}$. Figure 8 displays the structures of wellbore and the tubing string under construction.

\subsection{Wellbore temperature distribution}

Figure 9 displays the temperature distribution patterns of the fluids in tubing string and the annulus between tubing string and casing string. It can be observed that the full wellbore temperature drops significantly in high-rate, staged acid jobs, and the temperatures inside and outside the tubing string decrease more significantly in contrast with original formation temperature.

\subsection{Change in annular temperature between packers}

According to the multistage acid fracturing operation conditions, wellbore temperature is predicted and the change in annular temperature between packers with the injection time is plotted, as shown in Figure 10. Apparently, with the increase in pumping-injection time, annular temperature between packers drops gradually, and it is reduced to $50{ }^{\circ} \mathrm{C}$ after pumping injection for $30 \mathrm{~min}$. The temperature drops gradually slow down with the pump injection time, and finally, the annular temperature between packers is stabilized at $32{ }^{\circ} \mathrm{C}$. 


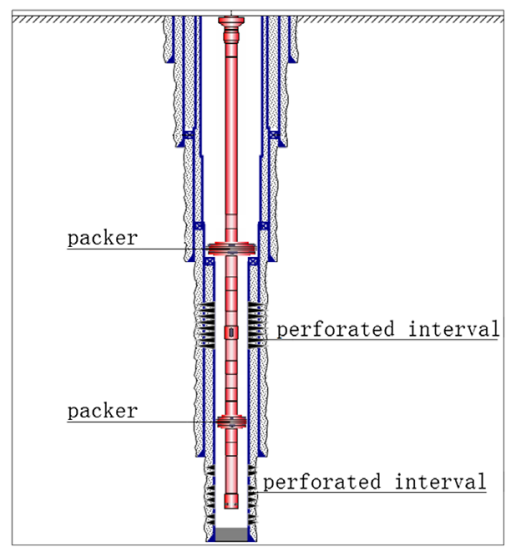

Fig. 8. Configuration and string diagram of the well.

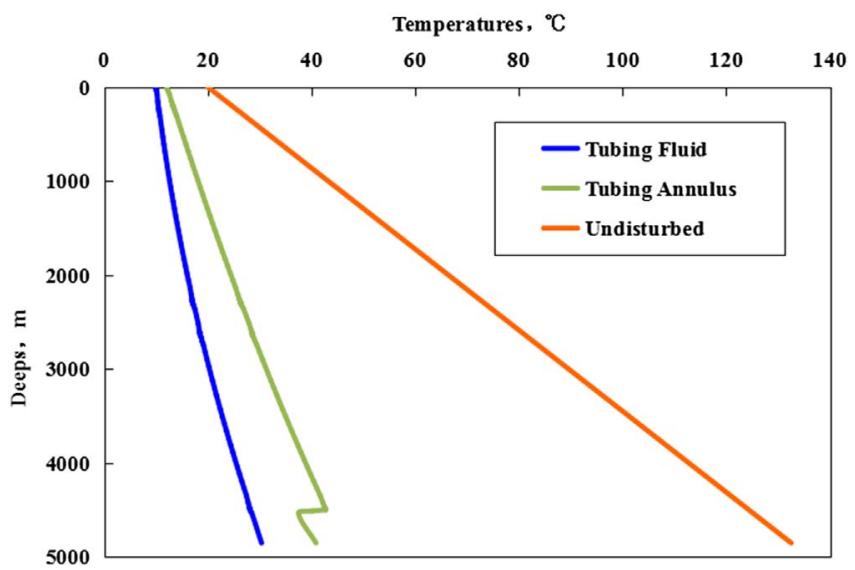

Fig. 9. The wellbore temperature field.

\subsection{Change in annular pressure between packers}

According to the change in annular temperature between packers, annular pressure between packers is predicted, and the temporal variation is shown in Figure 11. It can be observed that, at the beginning of injection, the wellbore temperature exhibits no drop. Under the pressure in the tubing string, annular pressure between packers rapidly increases to $98 \mathrm{MPa}$. Subsequently, with the continuous decrease in wellbore temperature, annular pressure between packers drops gradually, and it is reduced to approximately $30 \mathrm{MPa}$ after pumping injection for $40 \mathrm{~min}$. As the drop of formation temperature slows down and with the supplement of formation pressure, annular pressure between packers exhibits steady increase and finally stabilizes at a fixed value of $87 \mathrm{MPa}$.

\subsection{Verification of tubing string and packers}

The effect of multistage acid fracturing operation on annular pressure between packers is not taken into account when using traditional design methods. As stated above, this study assumes that the annular pressure between packers equals to the pore pressure in the formation. Based

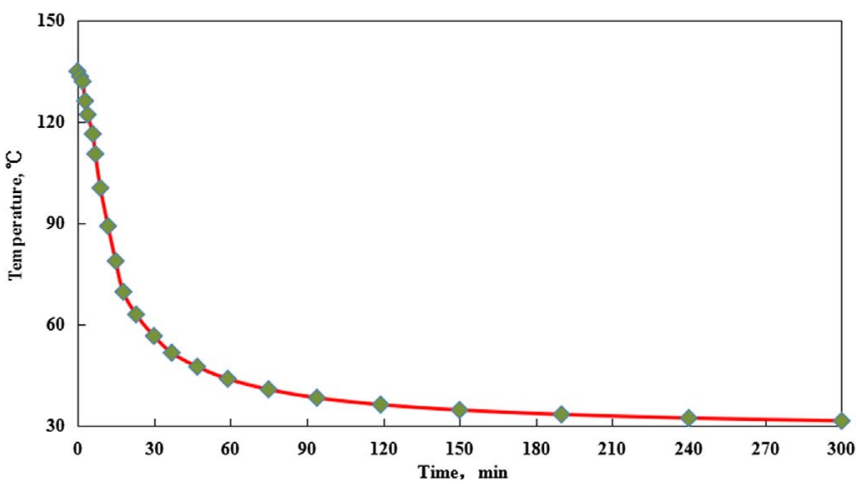

Fig. 10. Annular temperature change vs. Injection time.

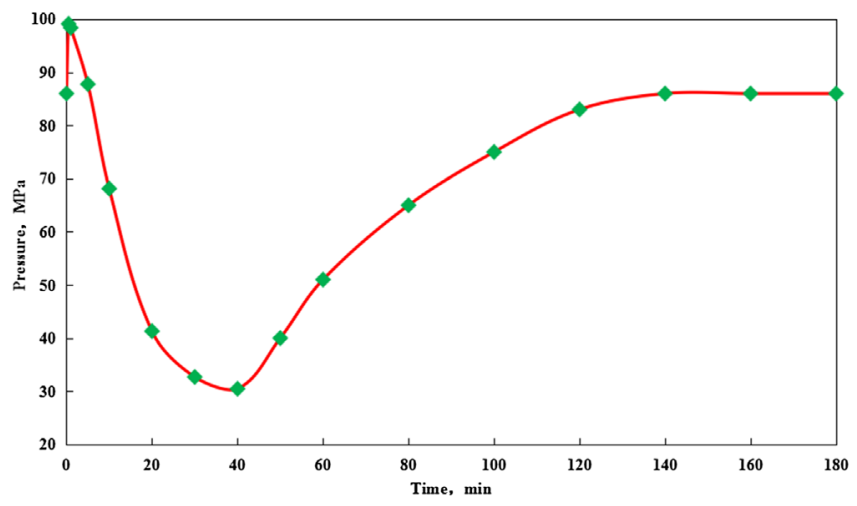

Fig. 11. Annular pressure change vs. Injection time.

on the prediction results of annular temperature and pressure between packers in multistage acid fracturing process, the intensities of tubing string and upper and lower packers are verified, and the verification results are shown in Figures 12-14. It can be observed that, using traditional design method, the tubing string and upper and lower packers all satisfy the requirements in terms of intensity and operation safety. By taking into account the decrease in annular pressure between packers induced by production increase, tri-axial stress on the tubing string between packers is smaller than the designed safety coefficient. Moreover, the loading conditions of both upper and lower packers exceed the envelope curves, while the tubing string and packers are all at high risks of failure. It is necessary to redesign the tubing string or adopt some effective riskmitigation measures.

\section{Research on mitigation measures}

\subsection{Analysis on risk mitigation approach}

String failure risk is because of decrease of the packer annular pressure which is caused by wellbore temperature decrease. That is, three conditions for the risk are wellbore temperature drop, isolation state of the two packers and lack of strength for tubing and packers. If one of the three 


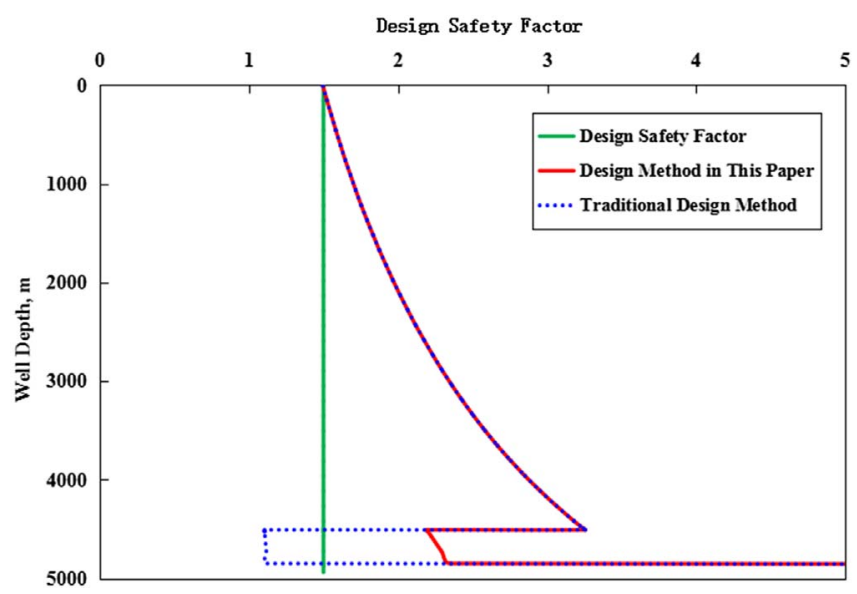

Fig. 12. Triaxial-stress calibrated results for the stimulation string for both methods.

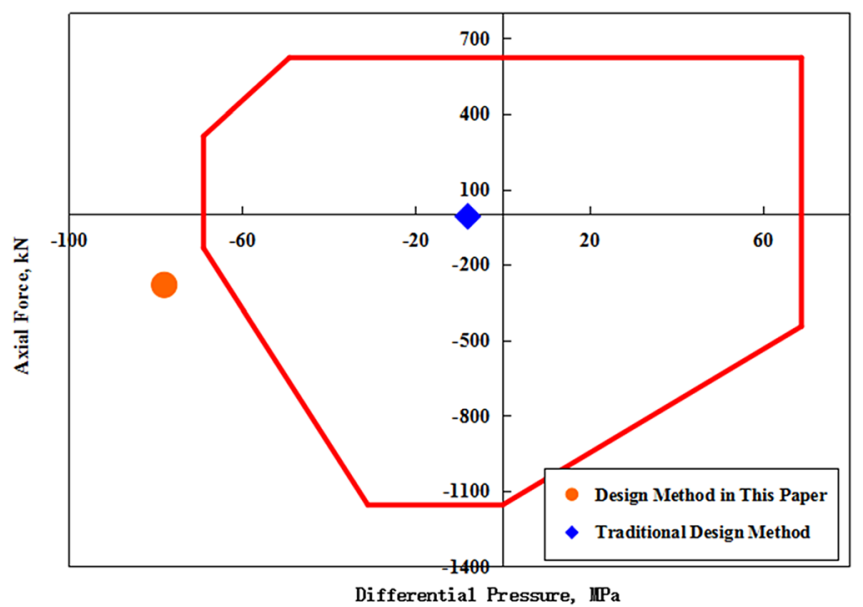

Fig. 13. Calibrated results for both methods against the upper packer operating envelope.

can be solved, string failure risk can be eliminated. Based on the mechanisms of the risks, the following risk precautionary ideas have been drown:

1. String failures can be prevented by means of uplifting packer pressure grade and tubing strength between the packers. Due to the fact of the great pumping pressure, after the packer annular pressure decreases to $0 \mathrm{MPa}$, it is impossible to select required tubing and packers. Therefore, this measure is not feasible.

2. Decrease wellbore temperature and improve acid fracturing fluid temperature and operation parameters to reduce wellbore temperature decrease, and then to prevent string failure by maintaining annular pressure between packers. However, Dibei gas field has commercial production only by means of large scale stimulation. Moreover, increasing temperature of acid may lead to the decrease of acid performance, increase of the corrosion on strings and cost for heating acid. Therefore, it is not feasible.

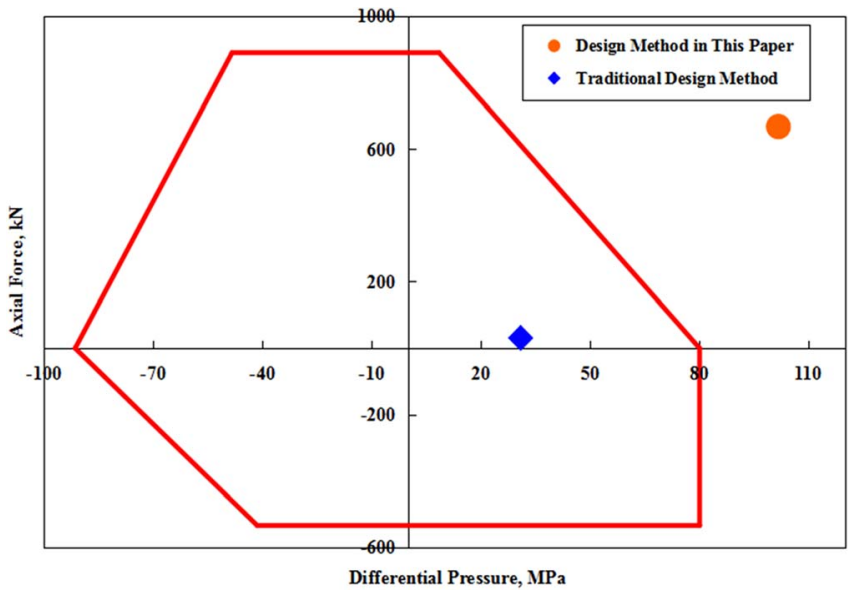

Fig. 14. Calibrated results for both methods against the lower packer operating envelope.

3. Break the isolation state between the two packers. Balance pressure between tubing-annulus and abovebelow packer, and then failure risks of string and packers can be prevented. Based on mechanism and technique, this approach is feasible. However, potential risks brought by perforated tubing still need to be further investigated.

After tapping the tubing, pressure between tubingannulus and packers will be the same. Stimulation string and upper and lower packer calibration results are shown in Figures 15-17. As are shown in Figures 15, 16 and 17, pipe string and upper-lower packers can meet the need of the design.

\subsection{Potential risk analysis of perforating tubing}

After perforation for tubing, fluid in tubing and annular space between packers can be connected with each other, therefore, can lead to the following risks:

1. When stimulating the lower interval, fluid diverters at perforations too much to realise staging stimulation aim. Diameter of equalizing orifice is $5 \mathrm{~mm}, 0.4 \%$ of tubing section. That is, when operation flow rate reaches to $4 \mathrm{~m}^{3} / \mathrm{min}$, flow rate at equalizing orifice is $0.016 \mathrm{~m}^{3} / \mathrm{min}$, and influence of orifice throttle on lower interval fracture is small. Therefore, this risk can be eliminated.

2. When stimulating the lower interval, great operation pressure will lead to the fracture of the production casing between two packers. Because inner compressive strength of the production casing between packers in Dibei gas field, dual packer production casing is safe when stimulating lower interval.

According to the above analyses, perforating several pressure release holes with diameter of $5 \mathrm{~mm}$ on tubing between two packers can effectively prevent failure risks of packers and strings during the staging stimulation treatment. 


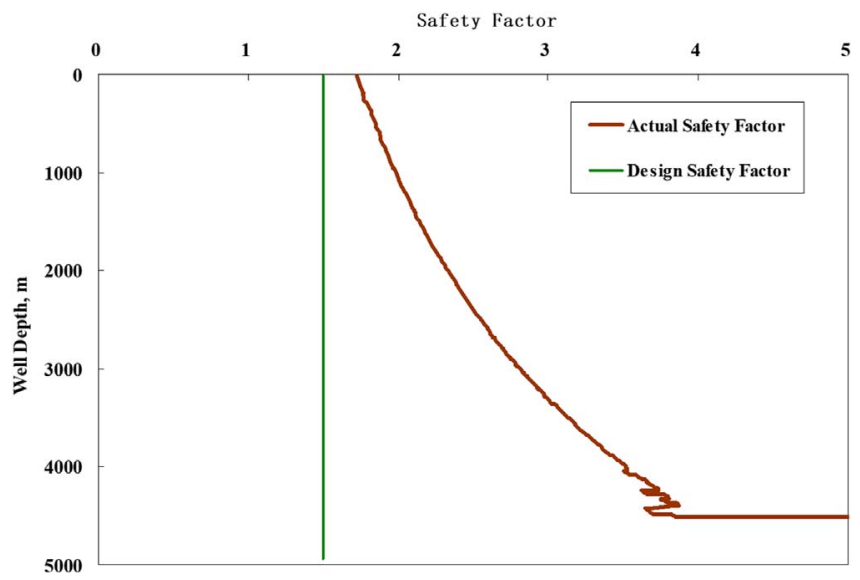

Fig. 15. Triaxial stress calibration result for stimulation string.

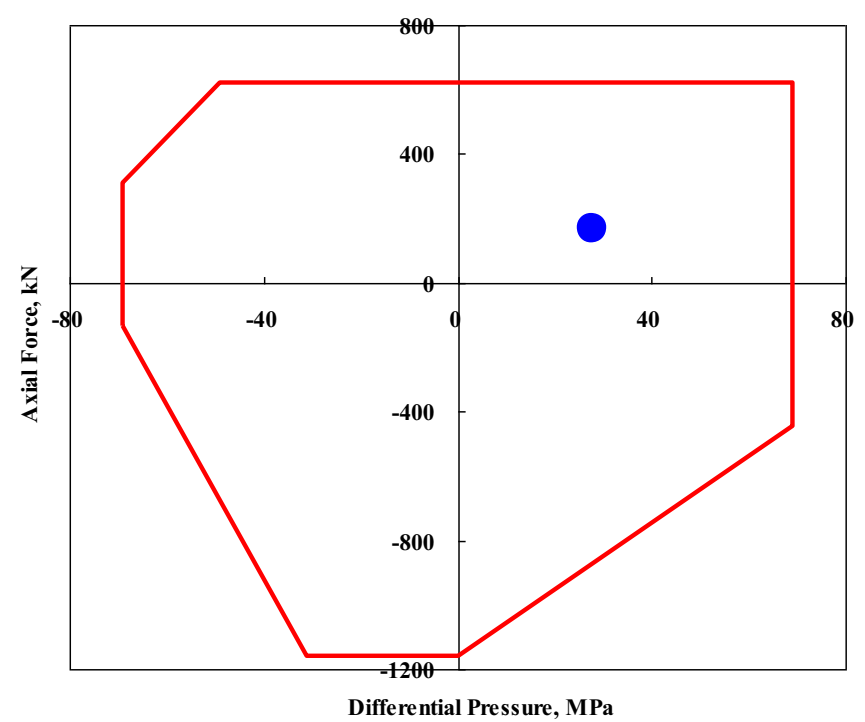

Fig. 16. Strength calibration of upper packer.

\section{Discussion and sensitivity analysis}

\subsection{Formation permeability}

Figure 18 displays the relationship between the change rule of annular pressure between packers and the permeability of the formation outside the annulus between packers. Overall, annular pressure between packers shows a more significant drop in the formation with lower permeability. At a permeability of $0.001 \mathrm{md}$, annular pressure between packers is reduced to $0 \mathrm{MPa}$ in multistage acid fracturing process, and the retention time can even last over $1 \mathrm{~h}$. As the formation permeability increases, the formation pressure supplement ability rises and annular pressure drops less significantly. As the formation permeability increases to $0.1 \mathrm{md}$, the reduction in annular pressure between packers can reach a maximum of $12 \mathrm{MPa}$.

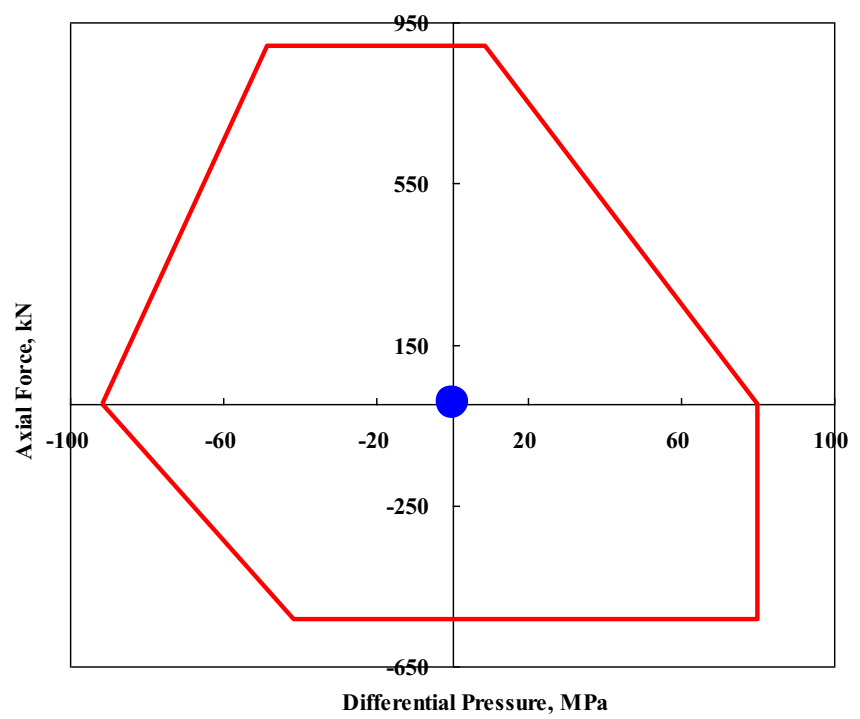

Fig. 17. Strength calibration of lower packer.

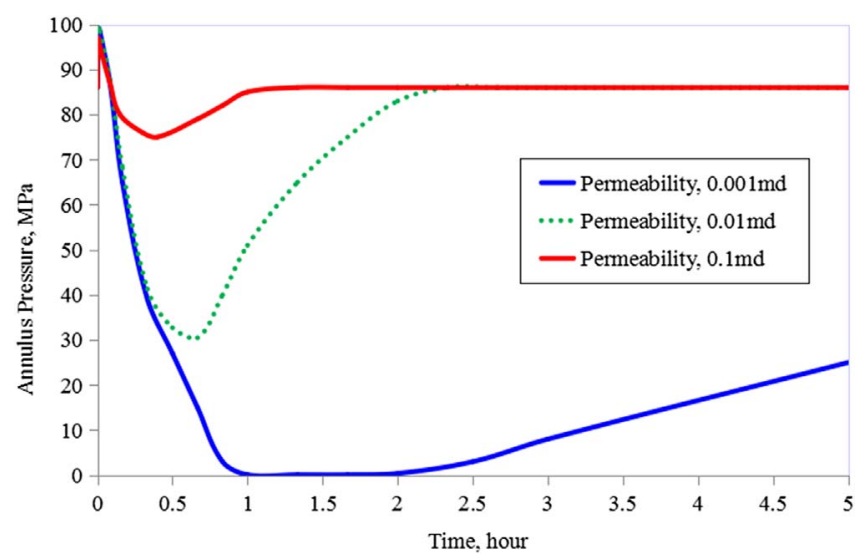

Fig. 18. Relation of annular pressure between packers and injection time under different reservoir permeability.

\subsection{Displacement of pump}

Figure 19 displays the relationship between the maximum reduction in annular pressure between packers and the displacement of pump. With the increase in displacement, the maximum reduction in annular pressure between packers increases more significantly. As the displacement of pump increases to $2 \mathrm{~m}^{3} / \mathrm{min}$, the maximum reduction in annular pressure between packers can reach up to $65 \mathrm{MPa}$.

\subsection{Formation pore pressure between packers}

Figure 20 displays the relationship between the maximum reduction in annular pressure between packers and the formation pore pressure. The maximum reduction in annular pressure between packers increases more obviously as the formation pore pressure rises. When the annular pore 


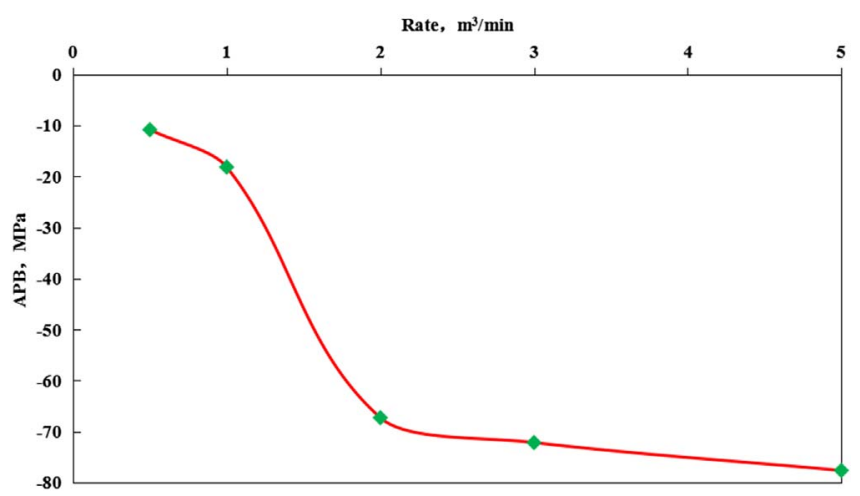

Fig. 19. Relation of displacement of pump and annular pressure drop between packers.

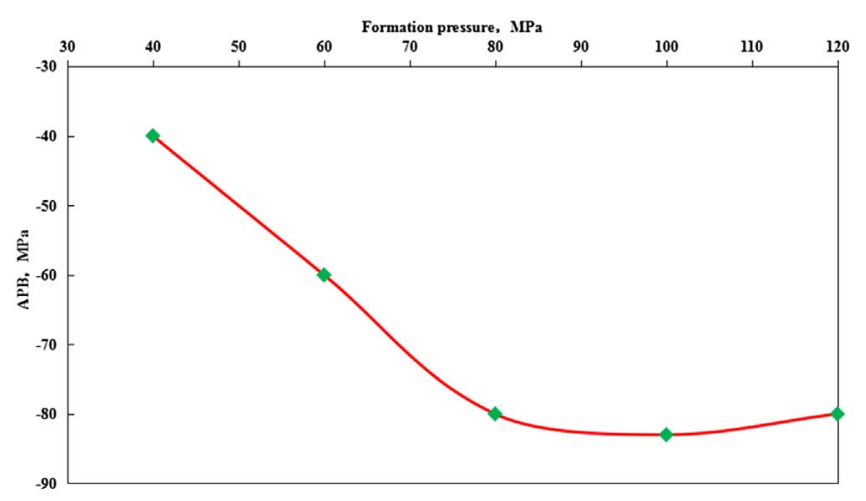

Fig. 20. Relation of formation pressure and annular pressure drop between packers.

pressure between packers equals to or is smaller than $80 \mathrm{MPa}$, annular pressure between packers during staged acid jobs can drop to $0 \mathrm{MPa}$. Therefore, the maximum reduction in annular pressure between packers equals to formation pore pressure. As the formation pore pressure increases gradually, the formation supplement ability can be steadily enhanced and the maximum reduction in annular pressure between packers drops.

\section{Conclusion}

In this study, by taking into account the effects of heat generated by friction and convection heat transfer, the transient prediction model of annular temperature field between packers in a high-pressure low-permeability well during high-rate, staged acid jobs under pumping injection condition was established. Moreover, the effects of the changes in wellbore temperature and pressure on annular volume between packers were analyzed. Moreover, in combination with the transient wellbore temperature prediction model, PVT state equation of annular fluid, the calculation model of tubing string radial deformation and the transient seepage equation of the formation, the transient prediction model of annular pressure between packers in multistage acid fracturing process was established.
The established prediction model of annular pressure between packers was then applied to the annulus between packers in a high-pressure low-permeability well during multistage acid fracturing period. In combination with the mechanical analysis results of the tubing string, it was found that the designed tubing string using traditional method is at a high risk of failure after considering the decrease in annular pressure between packers. Accordingly, the reduction in annular pressure between packers should be fully considered in the design of tubing string for highpressure low-permeability wells in multistage acid fracturing period.

For string failure risks of multilayer stimulation for high-pressure gas well, risk prevention measure study has been developed in terms of mechanism of decrease of annular pressure between packers resulted from wellbore temperature decrease. Based on the comparative analyses, safety performance of string and packers can be improved by means of perforating several holes on tubing between packers.

Acknowledgments. The authors are grateful for the support of National Natural Science Foundation of China (Grant no. 51704034), Open Fund (PLN201707) of State Key Laboratory of Oil and Gas Reservoir Geology and Exploitation (Southwest Petroleum University).

\section{References}

Ai S, Cheng L., Huang S., Liu H., Zhang J. (2015) A critical production model for deep HT/HP gas wells, J. Natural Gas Sci. Eng. 22, 132-140.

Azzola J.H., Tselepidakis D.P., Pattillo P.D., Richey J.F. (2007) Application of vacuum-insulated tubing to mitigate annular pressure buildup, SPE Drill. Complet. 22, 1, 46-51.

Bellarby J., Kofoed S.S., Marketz F. (2013) Annular pressure build-up analysis and methodology with examples from multifrac horizontal wells and HPHT reservoirs, in: Paper SPE 163557 Presented at the SPE/IADC Drilling Conference and Exhibition, Amsterdam, The Netherlands, 5-7 March.

Bradford D.W., Gibson D.H., Gosch S.W., Pattillo P.D., Sharp J.W., Taylor C.E. (2002) Marlin failure analysis and redesign: part 1 description of failure, in: IADC/SPE Drilling Conference, Dallas, USA, February 26-28.

Ding L. (2011) Mechanical study of testing string and its application in deep gas well with high pressure and high production, Doctoral Dissertation of Southwest Petroleum University, pp. 18-21.

Ezell R., Fontenot E.S., Robinson E.F., Cunningham L.E., Patrickis A. (2010) High performance aqueous insulating packer fluid improved flow assurance and reduced annular pressure buildup in ultra deepwater wells, in: SPE Deepwater Drilling and Completions Conference, Galveston, USA, October 5-6.

Gosch S.W., Horne D.J., Pattillo P.D., Sharp J.W., Shah P.C. (2004) Marlin failure analysis and redesign: part 3 - VIT completion with real-time monitoring, SPE Drill. Complet. 19, 02, 120-128.

Halal S., Mitchell R.F. (1994) Casing design for trapped annular pressure buildup, SPE 25694, Society of Petroleum Engineers, pp. 107-114. doi: 10.2118/25694-PA. 
Hasan R., Izgec B., Kabir S. (2010) Sustaining production by managing annular- pressure buildup, SPE Prod. Oper. 25, 02, 195-203.

Hasan A.R., Kabir C.S. (1991) Heat transfer during two-phase flow in wellbores: part I - formation temperaturein: $S P E$ Annual Technical Conference and Exhibition, Dallas, USA, October 6-9.

Hu W., Wang J., Zhang W. (2012) Confined annular pressure trap pressure prediction and release technology for deepwater drilling, Sino-glob, Energy 17, 08, 41-45.

Kan C., Yan J., Yu X., Meng W., Hu N., Zhou B., Zhang B., Hu Z. (2016) Numerical simulation of thermal stress on entrapped pressure of deepwater and further research on anti-thermal-stress casing tools, in: SPE/AAPG Africa Energy and Technology Conference, Society of Petroleum Engineers.

Oudeman P., Kerem M. (2006) Transient behavior of annular pressure buildup in HP/HT wells, SPE Drill. Complet. 21, 4, 234-241. SPE-88735-PA

Pattillo P.D., Cocales B.W., Morey S.C. (2006) Analysis of an annular pressure buildup failure during drill ahead, SPE Drill. Complet. 21, 04, 242-247.

Rizkiaputra R., Siregar R., Wibowo T., Mabunga S. (2016) A new method to mitigate annular pressure buildup by using sacrificial casing, case study: a deepwater well in Indonesia, Society of Petroleum Engineers.

Sathuvalli U.B., Payne M.L., Pattillo P.D., Rahman S., Suryanarayana P.V. (2005) Development of a screening system to identify deepwater wells at risk for annular pressure build-up, in: SPE/IADC Drilling Conference, Amsterdam, Netherlands, February 23-25.

Tahmourpour F., Hashki K., Hassan H.I.E.l. (2010) Different methods to avoid annular pressure buildup by appropriate engineered sealant and applying best practices (cementing and drilling), SPE Drill. Complet. 25, 02, 248-252.

Wang L., Gao B., Gao L., Tianxiang H. (2018) Prediction of annular pressure caused by thermal expansion by considering the variability of fluid properties, Appl. Therm. Eng. 141, 234-244.

Williamson R., Sanders W., Jakabosky T., Serio M., Grith J.E. (2003) Control of contained-annulus fluid pressure buildup, in: SPE/IADC Drilling Conference, Amsterdam, Netherlands, February 19-21.

Yang M., Meng Y., Li G., Deng J. (2013a) Effects of the radial temperature gradient and axial conduction of drilling fluid on the wellbore temperature distribution, Acta Phys. Sin. 62, 7, 79-84.

Yang J., Tang H., Liu Z., Yang L., Huang X., Yan D., Tian R. (2013b) Prediction model of casing annulus pressure for deepwater well drilling and completion operation, Petrol. Explor. Dev. 40, 5, 661-664.

Yin F., Gao D. (2014) Improved calculation of multiple annuli pressure buildup in subsea HPHT Wells, in: Paper SPE 170553 Presented at the IADC/SPE Asia Pacific Drilling Technology Conference and Exhibition, Bangkok, Thailand, 25e27 August.

Zhang Y., Li Z., Zhang L. (2010) Study on the casing strength of vacuum insulated shaft, Eng. Mech. 27, 05, 179-183. 